Camila Costa Torres

Júlia Issy Abrahão²

\section{A atividade de teleatendimento: uma análise das fontes de prazer e sofrimento no trabalho}

\section{Telemarketing activity: analysis of the sources of pleasure and suffering at work}

${ }^{1}$ Mestra em Psicologia pelo Instituto de Psicologia da Universidade de Brasília, Brasília, Brasil.

${ }^{2}$ Pós-doutorada pela Ecole Pratique des Hautes Etudes, Professora adjunta do Instituto de Psicologia da Universidade de Brasília, Brasília, Brasil.

\begin{abstract}
Resumo
O presente artigo dedica-se ao estudo da subjetividade dos trabalhadores no serviço de teleatendimento, indagando como as condições e a organização do trabalho, o conteúdo da tarefa e da atividade e os relacionamentos interpessoais contribuem para as vivências de prazer e sofrimento. Escolheu-se para o estudo empírico uma central de atendimento de um fundo de pensão privado. Para apreender o trabalho e compreender seus determinantes, buscou-se suporte teórico-metodológico na Ergonomia e na Psicodinâmica do Trabalho. Foram encontrados 26 indicadores de possíveis fontes de prazer ou sofrimento. A associação do indicador ao sentimento varia de sujeito para sujeito, em cada situação de trabalho. Os indicadores foram agrupados em 4 categorias, conforme as questões de estudo. A configuração da situação de trabalho como prazerosa ou não está vinculada à forma como os sujeitos se relacionam com a mesma. Assim, é fundamental a compreensão das categorias relacionadas ao estudo do prazer e do sofrimento como não estanques, pois elas se inter-relacionam, criando um cenário multideterminado.
\end{abstract}

Palavras-chaves: teleatendimento, prazer e sofrimento, subjetividade no trabalho, ergonomia, psicodinâmica do trabalho.

\begin{abstract}
This article deals with call center workers' subjectivity. It investigates how labor conditions and organization, content of the tasks and activity, as well as interpersonal relationships, add to the pleasure and suffering feelings experienced at work. A private pension fund call center was chosen for this empirical study. In order to learn about the task and understand its determinants, we searched for theoretical and methodological support in ergonomics and in labor psychodynamics. Twenty- six (26) indicators of possible sources of pleasure or suffering at work were found. The association of such indicators to their respective feelings varies from subject to subject, for each work-related situation. The indicators were grouped into 4 categories according to the issues under study. According to the way subjects relate to a situation at work they describe it either as being pleasant or unpleasant. Therefore, it is fundamental that the categories related to the study of pleasure and suffering are seen as being dynamic, for they interrelate, creating a multi-determined panorama.
\end{abstract}

Keywords: call center, answering phone calls, pleasure and suffering, work subjectivity, ergonomics, work psychodynamics. 


\section{Introdução}

As organizações, há muito tempo, de forma deliberada ou não, tentam ignorar a subjetividade que permeia as ações no trabalho. Grande parte dos projetos da produção é desenhada de forma a não contemplar espaços de manifestação dos afetos e dos sentimentos, o que acarreta a negação do papel da subjetividade no trabalho.

Ignorar essas vivências nas organizações muitas vezes é considerado um indicador de profissionalismo. Entretanto, na verdade, o que os trabalhadores sentem ou deixam de sentir afeta o seu modo de executar o trabalho, o seu desempenho e a sua produtividade.

Segundo Robbins (2004), desde o final do século XIX, com o surgimento da Administração Científica, formalizou-se a concepção de que uma organização bem administrada seria aquela capaz de eliminar as manifestações subjetivas dos trabalhadores, como, por exemplo, as emoções e outros sentimentos similares, ainda que se soubesse claramente que essas vivências são parte importante do desempenho das funções laborais e da saúde dos seres humanos.

Ainda hoje, muitas organizações se apóiam nesse pressuposto. Gestores e trabalhadores evitam abordar diretamente questões relativas aos afetos e aos sentimentos, como se fosse possível banir ou desconsiderar os efeitos dessas vivências no ambiente de trabalho. Todavia, observase que, em qualquer contexto, é cada vez mais difícil ignorar essa dimensão humana e, portanto, inevitavelmente, manifestações dessa natureza permeiam de maneira decisiva os contextos laborais.

Goussevskaia et al. (1999) discutem como, nas empresas modernas, o trabalho individual cede espaço ao trabalho em equipe. A subjetividade envolvida no trabalhar, a experiência e a visão pessoal tornam-se essenciais para o sucesso das empresas. Assim, elas buscam um novo perfil de trabalhador, no qual os conhecimentos, a educação geral, as experiências profissionais e pessoais são valorizados.

Os mesmos autores afirmam que as empresas modernas começaram a valorizar outros aspectos ao contratarem novos funcionários. Elas buscam trabalhadores que tenham iniciativa e demonstrem fidelidade, comprometimento e flexibilidade. Consideram que uma pessoa emocionalmente envolvida com o trabalho tende a se dedicar mais por associar o sucesso da empresa ao seu próprio.

No entanto, o que se verifica cotidianamente é que as pessoas adoecem cada vez mais. A hipótese defendida neste estudo é que esse processo de adoecimento tem sua origem no sofrimento resultante das contradições entre as exigências do trabalho e a organização do trabalho às quais os trabalhadores são submetidos.

Tendo em vista essa hipótese, é pertinente indagar como as condições de trabalho, a organização do trabalho, o conteúdo da tarefa e da atividade e os relacionamentos interpessoais contribuem para as vivências de prazer e sofrimento no trabalho.

Considerando o quadro atual de adoecimento entre as diferentes categorias de trabalhadores, as centrais de atendimento destacam-se como um campo privilegiado para este tipo de estudo. Elas empregam um contingente significativo de trabalhadores. Da mesma forma, são expressivos a rotatividade e o adoecimento nessa categoria profissional (TORRES, 2001; ASSUNÇÃO \& VILELA, 2004; SILVA, 2004). Por isso, escolheu-se para o estudo empírico uma central de atendimento de um fundo de pensão privado.

Para apreender o trabalho e compreender seus determinantes, buscou-se suporte teórico-metodológico na Ergonomia e na Psicodinâmica do Trabalho.

A Ergonomia e a Psicodinâmica do Trabalho - suas características e conexões

O desenvolvimento acelerado do setor de serviços trouxe novas questões e desafios para a Ergonomia, tais como problemas de produção e de saúde devido à importação de paradigmas tayloristas para as empresas de serviço, principalmente para aqueles considerados "de massa". Além das relações mais tradicionais entre colegas e com a hierarquia, comuns na indústria, a presença do cliente como co-autor do processo influencia significativamente o resultado do trabalho e também interfere na saúde dos trabalhadores.

Nessa perspectiva, a Ergonomia busca compreender o ser humano em sua unicidade, evitando a fragmentação do sujeito frente à realidade de trabalho. Essa visão de homem contempla a variabilidade e a complexidade do ser humano e do traba- 
lho. O trabalho é uma atividade que engaja e transforma o sujeito que a executa diante da variabilidade e das exigências das situações (TEIGER, 1992).

As prescrições da organização determinam o que e como deve ser feito e, geralmente, consideram apenas parte do que realmente o trabalho exige do trabalhador, cabendo a ele desenvolver mecanismos próprios, capazes de suprir este déficit, para realizar o que é esperado.

Duas dimensões, portanto, são determinantes para a compreensão do trabalho e dos mecanismos ativados na sua realização: a organização do trabalho e a atividade. A primeira refere-se ao conjunto de normas, regras e prescrições que determinam a forma como o trabalho deve ser realizado, tendo como objetivo principal a produção. Para cumpri-lo, estipulam-se os ritmos de trabalho, as pausas, os horários, os revezamentos, o treinamento.

Considera-se atividade a soma das prescrições da organização com as ações que o indivíduo realiza para dar conta das exigências da tarefa e com as suas características pessoais, experiência e treinamento (ABRAHÃO, 1993). É a partir das tarefas que, na atividade, se integram a prescrição e a imposição da empresa às características e aos conhecimentos dos trabalhadores. $\mathrm{Na}$ realização da atividade, independentemente da sua natureza, observa-se a solicitação de diferentes dimensões (física, cognitiva e psíquica) do funcionamento dos sujeitos.

É na esfera psíquica (espaço privilegiado de manifestação da subjetividade que permeia o trabalho) que ocorrem os processos de regulação psíquica, por meio dos quais se pode apreender a dinâmica dos processos psíquicos envolvidos na confrontação do sujeito com a realidade de trabalho.

O prazer está vinculado à realização, à satisfação ou à gratificação das pulsões. As pulsões são os desejos inconscientes dos indivíduos e, muitas vezes, apresentam-se ressignificadas, simbolizadas, com objetos e alvos definidos. Existem, então, diversos caminhos para se atingir a gratificação das pulsões. Nesses caminhos, pode ocorrer uma satisfação direta ou indireta da pulsão (MENDES, 1999).

O trabalho é um dos caminhos capazes de gratificar ou frustrar as energias pulsionais, tendo em vista seu papel no processo de sublimação. $\mathrm{O}$ processo de sublimação refere-se à derivação da pulsão para um alvo que visa a objetos socialmente valo- rizados. Trata-se do investimento da libido em um alvo socialmente aceito, de caráter não sexual, podendo ser considerado como um caminho indireto de gratificação pulsional (MENDES, 1999; KUPFER, 2000).

O trabalho revela-se, pois, como estruturador psíquico dos sujeitos. Em primeiro lugar por propiciar o atendimento de necessidades básicas de sobrevivência e segurança. Em segundo lugar por ser um caminho de gratificação pulsional, por meio do qual se torna possível a constituição da identidade pessoal e social dos sujeitos, pela valorização e pelo reconhecimento daquilo que é produzido e pelas ligações dos sujeitos com as tarefas, com os outros sujeitos e com o ambiente de trabalho (ABRAHÃO \& MENDES, 1995; MENDES, 1999).

Se o prazer resulta das gratificações pulsionais que o trabalho permite aos sujeitos, o sofrimento emerge dos conflitos entre os indivíduos e a organização do trabalho. Cada um deles é portador de uma história de vida singular, preexistente ao encontro com a situação de trabalho, geralmente caracterizada por regras e normas fixadas independentemente da sua vontade (DEJOURS, ABDOUCHELI \& JAYET, 1994).

$\mathrm{O}$ sofrimento surge quando o rearranjo da organização do trabalho não é mais viável, quando os trabalhadores esgotam suas possibilidades de adaptação espontânea do trabalho às suas características individuais. Nesse ponto, a energia pulsional que encontrava descarga no trabalho passa a se acumular no aparelho psíquico, provocando, assim, sentimentos de desprazer e tensão que podem afetar o sujeito e sua saúde das mais diversas formas.

O sujeito pensa sua relação com o trabalho, produz interpretações de sua situação e de suas condições e socializa esses produtos pessoais por meio dos atos subjetivos. O homem é um sujeito que reage e se organiza mental, afetiva e fisicamente em função de suas interpretações. Ele age sobre o processo de trabalho, contribuindo para a construção e a evolução das relações sociais implicadas no trabalho (DEJOURS, ABDOUCHELI \& JAYET, 1994).

Ao articular os resultados obtidos pelo método da Ergonomia com os da Psicodinâmica do Trabalho, considerando seu papel mediador no ato do trabalhar, elegeram-se como variáveis para análise: as condições de trabalho, a organização do trabalho, o conteúdo das tarefas e da atividade e os relacionamentos interpessoais no trabalho. 


\section{Metodologia}

Um dos eixos norteadores adotados em Ergonomia é a Análise Ergonômica do Trabalho (AET), na qual a análise da atividade é o fio condutor da ação.

A análise da atividade pressupõe um estudo pormenorizado dos sujeitos e dos processos envolvidos no desenvolvimento do trabalho. Assim, para a realização de um trabalho em Ergonomia, é fundamental a participação voluntária dos envolvidos no processo, caso contrário, torna-se inviável apreender a atividade e suas peculiaridades. Os procedimentos em Ergonomia não se apresentam como padrões rígidos e estáticos a serem seguidos uns após os outros; eles são referenciais que orientam a ação.

Ao propor o estudo da atividade de trabalho, o ergonomista almeja compreender como os sujeitos constroem o seu fazer cotidiano e como os trabalhadores atingem os objetivos propostos pela organização diante dos diversos imprevistos característicos das situações reais de trabalho. Para compreender a atividade, é necessário conhecer todo o ambiente sócio-técnico, as condições de trabalho, as relações sociais e hierárquicas, enfim, todos os elementos organizacionais que, de certa forma, são o cenário no qual se desempenha a atividade.

Ao revelar o fazer cotidiano dos sujeitos, é possível identificar: os principais constrangimentos, as principais dificuldades, a distância que existe entre as prescrições e a atividade, de forma a vislumbrar sugestões de possíveis melhorias a serem cogitadas para a situação em análise.

A análise da atividade permite colocar em evidência pontos fortes e fracos do trabalho, bem como da organização do trabalho vigente. Ou seja, é possível identificar focos de problemas ou melhorias no que se refere à saúde dos trabalhadores, à produtividade, às condições de trabalho e às relações como um todo dentro da empresa.

Em suma, pode-se afirmar que a ação ergonômica parte do conhecimento pormenorizado do trabalho para propor possíveis melhorias para a situação analisada, minimizando os impactos negativos do trabalho sobre as pessoas e sobre a empresa.

A ação em Psicodinâmica do Trabalho tem pressupostos e fundamentos diferenciados da ação Ergonômica. Enquanto a Ergonomia se debruça sobre o fazer dos trabalhadores, as características da empresa, as condições de trabalho e os modos de produção, a ação em Psicodinâmica do Trabalho enfoca as vivências subjetivas dos trabalhadores e sua relação com o trabalho por meio da compreensão da relação prazer/sofrimento e das estratégias defensivas desenvolvidas.

Apesar das diferenças entre as propostas, entre os arcabouços teóricos e metodológicos, é possível o diálogo entre essas duas abordagens, tendo em vista que elas podem ser complementares, principalmente diante do objetivo comum de sugerir melhorias para a situação de trabalho analisada.

A ação em Psicodinâmica do Trabalho permite a discussão das dificuldades e das vivências subjetivas em um espaço coletivo, no qual os participantes podem não apenas se expressar, mas também ressignificar muitos aspectos apresentados. O compartilhar de vivências subjetivas pode ser um início de transformação da relação dos sujeitos com os seus trabalhos.

Ao estudar a relação prazer/sofrimento é possível revelar certos impactos do trabalho sobre os sujeitos, sobre o equilíbrio psíquico e sobre a saúde dos trabalhadores.

Os métodos de análise empregados foram inspirados na Análise Ergonômica do Trabalho - AET (GUÉRIN et al., 2001) e na Ação em Psicodinâmica do Trabalho - APT (DEJOURS, 2003). Adotaram-se procedimentos relativos à tarefa e seus determinantes, realizaram-se observações globais da atividade de trabalho, entrevistas abertas e semi-estruturadas, discussões em grupo voltadas para questões ligadas à ação dos trabalhadores, suas vivências subjetivas e propostas para a transformação do trabalho.

\section{Sujeitos}

Participaram do estudo o universo dos funcionários alocados na central de atendimento, com idade variando entre 22 e 36 anos e escolaridade de nível médio a superior.

A operadora mais experiente ocupou, durante três anos, o cargo de representante da empresa em outra cidade, o que fez com que ela conhecesse muito bem os processos e procedimentos da empresa. Ao deixar o cargo de representante da empresa, ela 
começou a trabalhar na central de atendimento e acumulava, na época do estudo, dois anos de experiência nesse setor. Os demais operadores foram treinados por ela e efetivados no cargo a partir do segundo semestre do ano do estudo.

O cargo ocupado por eles é de nível médio e recebe na instituição a denominação de assistente técnico ou, mais especificamente, operador da central de atendimento.

\section{Instrumentos}

Os instrumentos utilizados para o desenvolvimento deste estudo foram:

\section{Entrevistas semi-estruturadas}

Entrevistas realizadas com os funcionários no local de trabalho, com um roteiro básico pré-estabelecido, visando a levantar dados sobre a situação de trabalho e suas peculiaridades a partir das representações dos trabalhadores.

\section{Entrevistas coletivas abertas}

Realizadas com os operadores no local de trabalho, sem um roteiro pré-estabelecido, com objetivo principal de criar um “espaço público” de discussão em que, a partir do relato coletivo sobre as vivências subjetivas no trabalho, fosse possível construir um ponto de vista compartilhado que subsidiasse mudanças no trabalho.

\section{Análise documental}

Análise de documentos referentes à hierarquia, à história e à descrição da instituição e de informações sobre os diferentes setores com os quais os operadores se relacionavam.

\section{Observações globais}

Observações globais da situação de trabalho, desde aspectos do ambiente até especificidades no desempenho da tarefa em busca de uma aproximação da realidade do trabalho desenvolvido.

\section{Procedimentos}

A primeira etapa do trabalho foi dedicada à compreensão do contexto no qual está inserida a Central de Atendimento (CA).

O primeiro contato na situação de trabalho foi formal, por meio de uma reunião com os gerentes administrativo, financeiro e de atendimento e comunicação. Nessa oportunidade foi explicitado o objetivo do estudo e solicitaram-se as devidas autorizações para a coleta de dados.
Uma apresentação da empresa foi realizada pelo gerente de atendimento e comunicação a fim de que houvesse aproximação da equipe de pesquisa com a empresa e seus processos.

As entrevistas semi-estruturadas exploraram:

- Os dados pessoais do funcionário (idade, tempo de serviço, experiência no cargo e cargo ocupado);

- As tarefas desenvolvidas pelos funcionários;

- As exigências das tarefas, o mobiliário, o espaço físico e os equipamentos;

- As relações de interdependência com os demais setores e gerências da empresa;

- As principais queixas dos funcionários.

Foram realizadas oito observações com registros da atividade desenvolvida e eventos ocorridos em horários variados da jornada de trabalho. Cada observação teve, em média, duração de uma hora. Os dados foram registrados em protocolos para posterior categorização e análise qualitativa.

As variáveis que constaram do plano de observações foram:

- Data;

- Horário;

- Atendente;

- Tempo de atendimento;

- Tipo de atendimento;

- Ligações realizadas para coleta de dados;

- Solicitação de informação ao colega;

- Assunto e respostas a e-mails, fax, cartas;

- Serviços externos;

- Saídas do posto.

Após a obtenção de dados por meio de entrevistas semi-estruturadas e observações, foram realizadas as entrevistas coletivas acerca do trabalho e das vivências subjetivas. Essas discussões ocorreram em um espaço reservado, na própria empresa, no qual os funcionários da CA foram convidados a apresentar suas opiniões sobre as dificuldades do trabalho e das vivências subjetivas relacionadas. O objetivo 
dessa ação era, primeiramente, viabilizar um espaço coletivo de discussão dos aspectos subjetivos do trabalho e, em um segundo momento, identificar possíveis formas de minimizar as dificuldades e as vivências negativas relatadas.

Os dados foram tratados em conjunto, visando a elaborar o diagnóstico da central.

\section{Resultados e discussão}

\section{O fundo de pensão}

O fundo de pensão estudado é uma entidade fechada de previdência privada que tinha, na época do estudo, um patrimônio bruto de 510 milhões de reais, 10.330 participantes ativos e 1.521 assistidos. Contava, à época, com aproximadamente 63 funcionários fixos.

A missão da empresa consiste em suplementar os benefícios assegurados pelo INSS aos empregados e seus familiares e promover, a longo prazo, o bem-estar social por meio de seu plano de benefícios.

A instância maior da empresa é o Conselho de Curadores, sendo secundado pela Diretoria Executiva e o Conselho Fiscal. A Diretoria Executiva é composta pelas Diretorias de Superintendência, Financeira e de Seguridade, que são compostas por nove gerências, todas de mesmo nível hierárquico. Este estudo foi realizado na Gerência de Atendimento e Comunicação.

\section{A central de atendimento}

A CA possui um acesso independente e se localiza no andar térreo do prédio da empresa, que possui quatro andares. Os clientes vinculados à organização são atendidos pessoalmente ou por telefone através dos ramais diretos e linhas 0800 . Uma outra forma de atendimento ao cliente é via e-mail. Os atendimentos são, em sua maioria, solicitações de cálculo de investimentos, empréstimos e aposentadorias, incluindo simulação com data fictícia ou prestação de informações sobre normas e regras. Qualquer alteração no cadastro dos usuários é solicitada à Gerência de Atendimento e Comunicação.

Outras atividades também são realizadas pelos funcionários do setor, entre elas: providenciar fotocópias de documentos na reprografia, receber e/ou preencher propostas de empréstimos, fazer requerimentos em geral e solicitar atualização de dados nas fichas cadastrais, além de preparar e enviar correspondências para os clientes, tanto via carta quanto via e-mail.
Os dados da clientela (listagens e documentos) ficam organizados em arquivos para consulta dos atendentes. Esses arquivos são encaminhados anualmente ao arquivo central, evitando o acúmulo de material.

Os atendentes fazem apelo às demais Gerências quando necessitam resolver algumas situações que extrapolam a autonomia da equipe da central, como, por exemplo, determinar a concessão de um empréstimo.

O local de trabalho está subdividido em três postos de trabalho informatizados individuais para o atendimento da clientela. Cada posto possui uma mesa em "L".

No posto de trabalho, encontram-se um terminal de computador, um aparelho de telefone, uma pasta com normas de atendimento e informações diversas, cronogramas/tabelas e calculadora.

\section{Indicadores de prazer e sofrimento no tra-} balho

Com o objetivo de identificar as fontes de prazer e sofrimento na atividade de atendimento ao público, este estudo apresenta 26 indicadores que podem ser associados às fontes de prazer ou de sofrimento. A associação do indicador ao sentimento varia de sujeito para sujeito, em cada situação de trabalho. Eles foram agrupados nas seguintes categorias:

- Condições físico-ambientais;

- Organização do trabalho;

- Conteúdo da tarefa e da atividade;

- Relacionamentos interpessoais no trabalho.

Essa relação tem sentido apenas em seu contexto, reafirmando o pressuposto de que os sentimentos de prazer e sofrimento são percebidos de forma distinta pelos sujeitos e constituem um construto dialético na medida em que coexistem nas situações de trabalho.

As condições físico-ambientais incluem as pressões físicas, mecânicas, químicas e 
biológicas do posto e do ambiente de trabalho (DEJOURS, ABDOUCHELI \& JAYET, 1994) e têm um papel na determinação do sofrimento ou do prazer quando interferem na atividade.

Ao trabalhar, os sujeitos coordenam ações motoras, racionais, motivacionais e emocionais. Isso é resultado da articulação necessária entre as esferas física, cognitiva e psíquica do agir. Assunção (2003), ao fazer uma síntese de estudos sobre saúde e trabalho, salienta que, nas centrais de atendimento, os custos físico e cognitivo são elevados, considerando a integração entre demandas variadas e as condições de trabalho inadequadas (ruído, mobiliário, espaço físico).

Quadro 1 Indicadores das fontes de prazer/sofrimento relacionados à categoria Condições Físico-Ambientais

\begin{tabular}{|l|l|l|}
\hline \multicolumn{1}{|c|}{ Categoria } & \multicolumn{1}{|c|}{ Indicadores } & \multicolumn{1}{c|}{ Exemplos } \\
\hline \multirow{2}{*}{ Condições físico-ambientais } & Falta de equipamento & Máquina de xerox \\
\cline { 2 - 3 } & $\begin{array}{l}\text { Isolamento físico do setor de trabalho } \\
\text { tizado informações no sistema informa- }\end{array}$ & $\begin{array}{l}\text { Muitas informações não constam no sistema informa- } \\
\text { tizado. Os funcionários são obrigados a se deslocar } \\
\text { freqüientemente para buscar informações em outros } \\
\text { setores }\end{array}$ \\
\cline { 2 - 3 } & Instrumental de trabalho fragmentado & $\begin{array}{l}\text { Deve consultar parte das informações no sistema e } \\
\text { outra nas listas e arquivos em papel }\end{array}$ \\
\hline
\end{tabular}

No Quadro 1, observa-se que elementos do ambiente físico, como o isolamento do setor e a falta de equipamentos, são considerados fontes de desgaste ou desconforto pelos trabalhadores, aproximando essas vivências da esfera do sofrimento.

Os trabalhadores queixam-se da necessidade de interromper todo atendimento presencial para deslocarem-se até a máquina de xerox para fazer cópias de documentos dos usuários. Esse deslocamento é considerado desgastante, não apenas pela distância, mas, principalmente, pelo fato de eles terem que "entrar e sair" da empresa o tempo todo e deixar o cliente esperando na central.

O sistema informatizado disponibilizado e a organização das informações apresentam, na opinião dos trabalhadores, diversas falhas que prejudicam o andamento do trabalho. O seu trabalho é fragmentado, pois a cada tarefa eles devem buscar simultaneamente informações no sistema e nos documentos em papel. Esse vai e vem contínuo, em que a atenção concentrada e a simpatia devem caminhar juntas ao longo da jornada, acaba por constituir uma fonte de desgaste para os trabalhadores.

A falta de equipamentos, instrumentos e materiais situa-se na mesma escala das condições físico-ambientais. Se o trabalhador não dispõe dos recursos materiais para desenvolver o seu trabalho, ele desenvolve estratégias para alcançar os objetivos, o que, a médio e longo prazos, pode acarretar sofrimento em virtude do esforço continuado para suprir as lacunas existentes.

A organização do trabalho é o mecanismo por meio do qual se regula o funcionamento e a atividade dos trabalhadores. Nessa categoria, situam-se as definições de ritmo, horários, turnos de trabalho, revezamentos, treinamentos, determinações quantitativas e qualitativas de produção, repartição das responsabilidades, hierarquia, comando, controle (ABRAHÃO, 1993; DEJOURS, ABDOUCHELI \& JAYET, 1994).

A rigidez da organização do trabalho retira a participação dos trabalhadores desse processo, limitando-os totalmente às determinações superiores. Sendo assim, não há a possibilidade dos trabalhadores buscarem uma adaptação espontânea do trabalho a sua realidade, o que pode gerar conflitos, insatisfações, sentimentos de indignidade, inutilidade, desqualificação e até depressão (DEJOURS, 1987). Esses sentimentos podem provocar ou agravar problemas de saúde dos trabalhadores, prejudicando seu desempenho, a produção e a instituição (ASSUNÇÃO \& VILELA, 2004). 
Quadro 2 Indicadores das fontes de prazer/sofrimento relacionados à categoria Organização do Trabalho

\begin{tabular}{|c|l|l|}
\hline \multicolumn{1}{|c|}{ Categoria } & \multicolumn{1}{|c|}{ Indicadores } & \multicolumn{1}{|c|}{ Exemplos } \\
\hline \multirow{2}{*}{ Organização do trabalho } & Mudanças nas determinações do trabalho & $\begin{array}{l}\text { Alterações constantes nas regras e nos instrumentos de } \\
\text { trabalho }\end{array}$ \\
\cline { 2 - 3 } & $\begin{array}{l}\text { Deslocamentos contínuos ao longo da } \\
\text { jornada }\end{array}$ & $\begin{array}{l}\text { Saídas do posto /setor para realizar partes da atividade } \\
\text { em outros setores da empresa }\end{array}$ \\
\cline { 2 - 3 } & Falta de acesso às informações & $\begin{array}{l}\text { Nem todas as informações disponibilizadas são sufi- } \\
\text { cientes para a realização da atividade }\end{array}$ \\
\cline { 2 - 3 } & $\begin{array}{l}\text { Interrupção da tarefa; transferência da } \\
\text { finalização da tarefa para o colega }\end{array}$ & Demandas simultâneas \\
\cline { 2 - 3 } & Pressão temporal para resposta & $\begin{array}{l}\text { Cobranças dos próprios operadores com relação à } \\
\text { demora nas respostas }\end{array}$ \\
\hline
\end{tabular}

As interrupções das tarefas, resultantes das demandas simultâneas, mobilizam diferentes recursos cognitivos dos atendentes e são fontes de desgaste na medida em que exigem mais atenção, concentração e controle dos erros. Além disso, afastam os sujeitos da finalização da tarefa e a possibilidade de atribuir um sentido ao seu trabalho (Quadro 2).

A pressão temporal a que os atendentes estão submetidos resulta de dupla exigência: os usuários pressionam os atendentes para obter as informações e os atendentes, por sua vez, pressionam seus colegas de outros setores para liberarem as informações que são necessárias para o atendimento que estão prestando. Essa relação de dependência dos demais setores afeta diretamente o desempenho da atividade dos atendentes, bem como a sua relação com os usuários.

A organização do trabalho na situação analisada permite aos trabalhadores um espaço para a manifestação de suas dificuldades, mas não há eficiência nesse processo, porque as mudanças não são operacionalizadas. Isso leva os trabalhadores a desenvolver estratégias para conviver com a situação da maneira como ela se configura. A seguir serão apresentadas algumas dessas estratégias.

A organização do trabalho não é extremamente rígida, mas também não oferece muitos recursos para a busca do equilíbrio. São os trabalhadores que se adaptam e convivem com as dificuldades.

Abrahão e Torres (2004) apresentam resultados que mostram como os elementos da organização de trabalho em uma central de atendimento podem contribuir ou dificultar a execução das tarefas e sua repercussão sobre as vivências de prazer e sofrimento. As autoras discutem o sofrimento vivenciado pelos atendentes, uma vez que as prescrições não permitem alterações dos procedimentos e a transgressão às normas torna-se uma estratégia dos trabalhadores para se adaptarem às situações e se fazerem entender pelos usuários. Nesse caso, a transgressão torna-se uma fonte de prazer, na medida em que os atendentes são capazes de transformar o sofrimento patogênico em sofrimento criativo.

A partir do momento em que a organização do trabalho assume uma configuração flexível, resultante de compromissos e negociações entre os envolvidos no processo, ela pode tornar-se um verdadeiro recurso para o equilíbrio psíquico (MENDES, 1999), funcionando como suporte para o desenvolvimento da atividade.

A relação que o trabalhador estabelece com sua tarefa é um outro aspecto que influencia a saúde e a produção. O nível de investimento no trabalho realizado pelos sujeitos, qualquer que seja seu tipo, afetivo ou material, geralmente é determinado pela natureza das tarefas e conseqüentemente da atividade.

A atribuição de sentido às tarefas está vinculada a um processo denominado ressonância simbólica, que é caracterizado pela reconciliação entre o inconsciente dos sujeitos e os objetivos da produção (MENDES, 1995). 
Quadro 3 Indicadores das fontes de prazer/sofrimento relacionados à categoria Conteúdos da Tarefa e da Atividade

\begin{tabular}{|c|c|c|}
\hline Categoria & Indicadores & Exemplos \\
\hline \multirow{9}{*}{$\begin{array}{l}\text { Conteúdos da tarefa } \\
\text { e da atividade }\end{array}$} & Variabilidade das tarefas & Tarefas de natureza diferenciada ao longo da jornada \\
\hline & Simultaneidade de tarefas & Realização de mais de uma tarefa ao mesmo tempo \\
\hline & Responsabilidade & $\begin{array}{l}\text { Responsabilidade dos operadores, pois são eles que apresen- } \\
\text { tam as condições para auferir dos benefícios }\end{array}$ \\
\hline & Tarefas de conteúdo vazio & Simples transferências de chamadas \\
\hline & Copiar e arquivar documentos (tarefas repetitivas) & $\begin{array}{l}\text { Necessidade de copiar e arquivar todos os documentos utiliza- } \\
\text { dos, recebidos e enviados aos participantes }\end{array}$ \\
\hline & Contato com o usuário & Contato face a face com o usuário \\
\hline & Ritmo de trabalho imposto pelo usuário & Atividade vinculada ao surgimento da demanda do usuário \\
\hline & Estratégia operatória de coleta de informações & $\begin{array}{l}\text { Busca de informações em outros setores com deslocamentos } \\
\text { ou por telefone }\end{array}$ \\
\hline & $\begin{array}{l}\text { Estratégia operatória de troca de experiência com } \\
\text { os colegas }\end{array}$ & Em situações problemas \\
\hline
\end{tabular}

Na situação analisada, a diversidade de tarefas pode ser vista como favorável ou não, pois, para alguns trabalhadores, pode ser fonte de sofrimento em virtude da grande quantidade de informações e procedimentos a aprender. Para outros, a diversidade de situações às quais são confrontados evita a repetitividade, criando desafios e favorecendo o crescimento profissional.

Outra condição interessante na central é o paradoxo que se instaura na atividade. Ao mesmo tempo em que os atendentes são desafiados na realização de algumas tarefas que solicitam diferentes mecanismos cognitivos, eles são subtilizados em outras. Um exemplo é a realização de diversos tipos de cálculos de benefícios e empréstimos, com índices diferenciados para cada caso, em contraposição às tarefas de cópias e arquivamento de materiais, consideradas como vazias e repetitivas.

Além disso, estão submetidos às tarefas interferentes em diferentes momentos da jornada e ao peso da responsabilidade dos seus cálculos perante os usuários.

O contato com o usuário também é considerado pelos operadores fonte de sofrimento, que, além de mobilizar a subjetividade, afeta a saúde do trabalhador. Os atendentes se queixam da dificuldade em lidar com os usuários e suas problemáticas pessoais. Conviver no dia-a-dia com o sofrimento do outro sem grandes possibilidades de amenizá-lo não é sem conseqüência para o atendente. $\mathrm{Na}$ central, os atendentes se relacionam com o público de duas formas distintas. Alguns usuários vão pessoalmente ao fundo de pensão e outros buscam a informação por telefone. Nesse processo, os atendentes se vêem na condição de escuta. Sempre são histórias permeadas de sofrimento, como morte, doenças ou, ainda, dificuldades financeiras. Eles relatam que essa escuta acaba por sensibilizá-los e afirmam também que a relação face a face é extremamente desgastante, pois não conseguem abstrair o sofrimento do outro. A única forma de minimizar essa vivência desagradável é pressionar os colegas para que os usuários tenham o encaminhamento de seus processos agilizado. Ao agir e obter resultados significativos, eles operam a transformação do sofrimento resultante dessa relação.

Wisner (1987) ressalta que as situações de trabalho que podem causar sofrimentos mental e físico de maior intensidade são aquelas que aliam a forte carga de trabalho com as exigências do atendimento ao público. Outros indicadores de prazer/sofrimento relacionados ao atendimento ao público são apresentados também no Quadro 3 .

Uma forma de reagir às dificuldades encontradas é o desenvolvimento de estratégias operatórias, revelando um enfrentamento do sofrimento ou uma busca pelo prazer no trabalho. Nesse caso, foram levantadas duas estratégias consolidadas pelos trabalhadores: a estratégia de coleta 
de informações e a de troca de informações com os colegas.

As estratégias operatórias são definidas por Silvino \& Abrahão (2003, p.15) como:

o processo de categorização, resolução de problemas e tomada de decisão que resulta em um modo operatório (seqüência de ações e operações) adotado pelo sujeito na interação com o artefato.

Segundo os autores, as estratégias operatórias estão intimamente relacionadas às competências e ao processo de regulação no trabalho. São ações dos operadores que podem favorecer o desempenho no trabalho ou minimizar a probabilidade de erros. Pode-se inferir que o uso de estratégias operatórias favorece o equilíbrio psíquico, visto que é uma das formas utilizadas pelos trabalhadores para regular a situação.

Outro fator que contribui para a busca do equilíbrio psíquico no ambiente de trabalho observado na situação em questão é o papel do coletivo de trabalho na categoria de relacionamentos interpessoais no trabalho, mostrado no Quadro 4.

Quadro 4 Indicadores das fontes de prazer/sofrimento relacionados à categoria Relacionamentos Interpessoais no Trabalho

\begin{tabular}{|c|c|c|}
\hline Categoria & Indicadores & Exemplos \\
\hline \multirow{8}{*}{$\begin{array}{l}\text { Relacionamentos interpessoais no } \\
\text { trabalho }\end{array}$} & Coletivo de trabalho & $\begin{array}{l}\text { Relação interpesssoal positiva com os colegas do } \\
\text { setor, da empresa e superiores }\end{array}$ \\
\hline & Forma de expressão do usuário & Expressões grosseiras \\
\hline & Reações dos atendentes às falas dos usuários & $\begin{array}{l}\text { Expressões faciais e gestos dos operadores, mani- } \\
\text { festações de dificuldade ou de cansaço }\end{array}$ \\
\hline & Repetitividade da fala do usuário & $\begin{array}{l}\text { O usuário repete a pergunta ou a resposta do } \\
\text { operador }\end{array}$ \\
\hline & Falta de objetividade do usuário na conversa & Dificuldade de expressão do usuário \\
\hline & Desabafo do usuário com o atendente & $\begin{array}{l}\text { Usuário conta sua história de vida, detalhando seu } \\
\text { contexto }\end{array}$ \\
\hline & Demandas imprecisas ou problemáticas & $\begin{array}{l}\text { Usuário não sabe o que quer ou seu problema vai } \\
\text { além da alçada do atendente }\end{array}$ \\
\hline & $\begin{array}{l}\text { Busca de uma linguagem que permita ao } \\
\text { usuário compreender a sua resposta }\end{array}$ & $\begin{array}{l}\text { Diversidade das formas de explicação visto a varia- } \\
\text { bilidade dos usuários }\end{array}$ \\
\hline
\end{tabular}

$\mathrm{Na}$ central analisada, os atendentes recorriam freqüentemente ao suporte dos colegas próximos ou a outros alocados em gerências diferentes das deles, coexistindo em uma estrutura muito semelhante àquelas do coletivo de trabalho. Esse apoio desempenha um papel fundamental no equilíbrio dos atendentes. A possibilidade de troca de informações e a cooperação estabelecida funcionam como mediadores da saúde. Os sujeitos, ao encontrarem dificuldades, recorrem ao coletivo, buscando apoio e, assim, a partir das suas experiências, atualizam as suas competências. Essas relações se estabelecem de forma harmoniosa entre experts e debutantes e também entre sujeitos de competências semelhantes. Cabe ressaltar que esse recurso é bastante utilizado em situações nas quais a importância do coletivo é reconhecida pela organização e nas quais os níveis de tratamento de informações e resolução de problemas são freqüentes.
Segundo Dejours, Abdoucheli e Jayet (1994), as estratégias coletivas são mecanismos por meio dos quais os trabalhadores buscam modificar, transformar e minimizar a percepção da realidade de sofrimento a que estão circunscritos. Esse é um processo de cunho mental, tendo em vista a manutenção da realidade e da situação imposta aos trabalhadores.

Todavia, se o suporte oferecido pelo coletivo é uma fonte de prazer, a relação com o usuário, quase sempre, é fonte de sofrimento. As freqüentes reclamações do público relativas ao desempenho da atividade podem contribuir para o aumento do desgaste dos trabalhadores, principalmente daqueles que trabalham em instituições que atendem aos mais diferentes tipos de público, como é o caso do fundo de pensão analisado.

O trabalho de atendimento ao público exige, constantemente, uma postura de amabilidade, cordialidade e paciência. 
Em serviços nos quais os atendentes estão vinculados a outras pessoas ou o trabalho é mediado por algum aparato tecnológico, essa exigência pode ser fonte de desgaste. Isso ocorre, pois, quando a demanda do usuário é problemática ou ultrapassa as capacidades e os recursos do trabalhador, que fica impossibilitado de desenvolver sua atividade, frustrando suas expectativas e seus objetivos no trabalho. Observou-se isso no estudo da Central do Fundo de Pensão, em que muitas vezes os atendentes dependem do trabalho e das informações de outros setores para realizar sua atividade.

Esses sentimentos também são identificados na relação do trabalho desenvolvido com o restante da instituição. Ao mesmo tempo em que os atendentes valorizam o acesso às diferentes estruturas, eles se queixam da falta de reconhecimento, por parte do conjunto da instituição, da atividade desempenhada, do seu esforço e do seu valor.

A diferença entre as expectativas que os atendentes tinham do trabalho no início e depois de alguns anos de experiência é notória. A ilusão inicial de poder resolver tudo, atender aqueles que precisam, vai, aos poucos, sendo substituída por uma visão mais pragmática, fruto, por exemplo, de experiências que deram certo. O que é mais problemático e fonte de maior sofrimento são as situações de impasse, nas quais eles se sentem incapazes de dar uma solução, para encaminhar o problema, ao mesmo tempo em que presenciam, diariamente, o sofrimento dos clientes.

\section{Conclusão}

O trabalho, conforme ficou demonstrado, é um lugar no qual coexistem sentimentos de prazer e sofrimento. Porém, muitas vezes, o encontro com o trabalho é considerado um desencadeador de sofrimento, tendo em vista o conflito entre os desejos dos sujeitos e as imposições organizacionais. O prazer é considerado resultante da dinâmica de transformação do sofrimento e também como resultado direto do trabalho, considerando os aspectos do processo sublimatório, isto é, o trabalho como fonte de gratificação psíquica. Nessa perspectiva, o trabalho também pode ser marcado pelo encontro com o prazer e o sofrimento pode ser considerado como mobilizador para a busca de prazer.

A configuração da situação de trabalho como prazerosa ou não está vinculada à

\section{Referências bibliográficas}

ABRAHÃO, J. I. Ergonomia: modelo, métodos e técnicas. In: CONGRESSO LATINOAMERICANO, 2, SEMINÁRIO BRASILEIRO DE ERGONOMIA, 6, 1993, Florianópolis. Anais... Florianópolis: Abergo/Fundacentro, 1993.

ABRAHÃO, J. I.; MENDES, A. M. Organização do trabalho e vivências de prazer-sofrimento do trabalhador: abordagem psicodinâmica. Psic.: Teor. e Pesq., v. 12, n. 2, p. 179-184, 1996. forma segundo a qual os sujeitos se relacionam com a situação. Assim, é fundamental a compreensão das categorias relacionadas ao estudo do prazer e do sofrimento como não estanques. Elas se inter-relacionam, criando um cenário multideterminado.

As reflexões até aqui desenvolvidas apontam as variáveis prazer e sofrimento como resultantes da relação do indivíduo com a organização, da relação consigo mesmo, das relações entre indivíduos e com o meio no qual estão inseridos. Pode-se dizer ainda que cada relação é determinada pela história passada dos sujeitos e pela tensão dialética entre os sentimentos de prazer e sofrimento nas situações de trabalho. Assim, o que para uns pode ser sentido como prazeroso, não o será necessariamente para outros.

ABRAHÃO, J. I.; TORRES, C. C. Entre a organização do trabalho e o sofrimento: o papel de mediação da atividade. Rev. Produção, v. 14, n. 3, p. 67-76, 2004.

ASSUNÇÃO, A. A. Uma contribuição ao debate sobre as relações saúde e trabalho. Ciênc. saúde coletiva, v. 8, n. 4, p. 10051018, 2003.

ASSUNÇÃO, A. A.; VILELA, L. V. Os mecanismos de controle da atividade no setor de teleatendimento e as queixas de cansaço e esgotamento dos trabalhadores. 
Cad. Saúde Pública, v. 20, n. 4, p. 10691078, 2004.

DEJOURS, C. A loucura do trabalho. São Paulo: FTA/Oboré, 1987.

$$
\text { L'évaluation du travail à }
$$

l'épreuve du réel. Critique des fondements de l'évaluation. Paris: INRA, 2003.

DEJOURS, C.; ABDOUCHELI, E.; JAYET, C. Psicodinâmica do trabalho: contribuições da escola dejouriana à análise da relação prazer, sofrimento e trabalho. São Paulo: Atlas, 1994.

GOUSSEVSKAIA, A. et al. A empresa moderna e o processo de gestão de recursos humanos. In: PIMENTA, S. (org.). Recursos Humanos: uma dimensão estratégica. Belo Horizonte: UFMG, 1999.

GUÉRIN, F. et al. Compreender o trabalho para transformá-lo: a prática da Ergonomia. São Paulo: Edgar Blücher, 2001.

KUPFER, M. C. Freud e a educação. 3ed. São Paulo: Scipione, 2000.

MENDES, A. M. Aspectos psicodinâmicos da relação homem-trabalho: as contribuições de C. Dejours. Psicologia Ciência e Profissão, n. 1-3, p. 34-38, 1995.

Valores e vivências de prazersofrimento no contexto organizacional.
1999. Tese (Doutorado em Psicologia), Universidade de Brasília, Brasília, 1999.

ROBBINS, S. P. Fundamentos do Comportamento Organizacional. 7ed. São Paulo: Prentice Hall, 2004.

SILVA, A. M. A regulamentação das condições de trabalho no setor de teleatendimento no Brasil: necessidades e desafios. 2004. Dissertação (Mestrado em Saúde Pública), Universidade Federal de Minas Gerais, Belo Horizonte, 2004.

SILVINO, A. M. D.; ABRAHÃO, J. I. Navegabilidade e inclusão digital: navegabilidade e competência. RAE eletrônica, v. 2, n. 2, 2003. Disponível em: http://www.unb. br/ip/labergo/sitenovo/imgprod/producao. htm. Acesso em 16 jul 2005.

TEIGER, C. Le travail, cet obscur objet de l'érgonomie. Actes du Colloque Interdisciplinaire "Traval: Recherche et prospective". Thème Transversal n. 1. Concept de Travail. CNRS, PIRTTEM, ENS de Lyon, 1992.

TORRES, C. C. A atividade nas centrais de atendimento: outra realidade, as mesmas queixas. 2001. Dissertação (Mestrado em Psicologia), Universidade de Brasília, Brasília, 2001.

WISNER, A. Por dentro do trabalho - Ergonomia: método e técnica. São Paulo: FTA/Oboré, 1987. 